\title{
Brief Communication: The effect of submerged vents on probabilistic hazard assessment for tephra fallout
}

\author{
R. Tonini ${ }^{1}$, L. Sandri ${ }^{2}$, A. Costa ${ }^{2}$, and J. Selva ${ }^{2}$ \\ ${ }^{1}$ Istituto Nazionale di Geofisica e Vulcanologia, Sezione di Roma 1, Rome, Italy \\ ${ }^{2}$ Istituto Nazionale di Geofisica e Vulcanologia, Sezione di Bologna, Bologna, Italy \\ Correspondence to: R. Tonini (roberto.tonini@ingv.it)
}

Received: 1 August 2014 - Published in Nat. Hazards Earth Syst. Sci. Discuss.: 28 November 2014 Revised: 11 February 2015 - Accepted: 11 February 2015 - Published: 4 March 2015

\begin{abstract}
Many volcanic systems are partially or entirely submerged, implying that vents may open underwater. The effect of submerged vents on probabilistic volcanic hazard assessment (PVHA) for tephra fallout has always been neglected, introducing potentially uncontrolled biases. We present a strategy to quantify the effect of submerged vents on PVHA for tephra fallout, based on a simplified empirical model in which the efficiency of tephra production decreases as a function of the water depth above the eruptive vent. The method is then applied to Campi Flegrei caldera, comparing its results to those of two reference end-member models and their statistical mixing.
\end{abstract}

\section{Introduction}

Several very hazardous volcanic systems are located very close to seas, oceans or lakes worldwide and their vents can be partially submerged by water. As a consequence, the vent of possible future eruptions for such volcanoes could be both inland or offshore, inferring the need of considering the possible different eruptive behaviour of the submerged opening vents with respect to the subaerial ones. Notorious examples of high-risk volcanoes with potentially submerged vents are, among many others, the Auckland Volcanic Field (New Zealand), Rabaul caldera (Papua New Guinea), Santorini (Greece), and the Campi Flegrei caldera ( $\mathrm{CFc}$, Italy).

The high risk associated with volcanic activity at some of these partly submerged volcanoes motivated many efforts to estimate the hazard posed on the surrounding high-density populated areas, for different possible hazardous volcanic outcomes (e.g. Sandri et al., 2012, at the Auckland Vol- canic field). Several hazardous phenomena are associated with eruptions in shallow waters; however, in the present communication, the focus is on tephra fallout hazard which can impact very large areas far from the vent.

Tephra fallout hazard assessment is commonly achieved by using different methodologies ranging from mapping the geological record (e.g. Orsi et al., 2004) to modelling a few representative scenarios (e.g. Costa et al., 2009) or, more recently, applying probabilistic methods (e.g. Selva et al., 2010). However, in all of the studies on tephra fallout, the effect of potentially submerged vents on the computed hazard has never been explored. This motivated us to propose two new possible strategies to analyse the tephra fallout probabilistic volcanic hazard assessment (PVHA), so as to take into account the effect of the water above a submerged vent on subaerial tephra production. In particular, on one hand, we propose a new model consisting of a statistical mixing (Selva et al., 2014) of the two PVHAs based on two endmember assumptions on the efficiency of submarine vents to produce subaerial tephra: (i) the effect of the sea as null, i.e. as if every possible vent behaves as subaerial, and (ii) the effect of the sea as a cap that totally inhibits the injection of tephra into the atmosphere. On the other hand, we propose an empirically based simple model in which the efficiency of submerged eruptions in producing subaerial tephra linearly decreases as a function of the water depth above the eruptive vent, up to a maximum depth $\left(D_{\max }\right)$ at which such production is totally suppressed.

The goal of the paper is to explore the sensitivity of PVHA results when considering the inhibiting effect of the overlying water on subaerial tephra production, in the case that the vent opens offshore. Such sensitivity is evaluated by com- 
paring the two PVHAs resulting from the proposed models with the two end-member PVHAs. We also check the sensitivity of the PVHA results of the empirically based model against the value of $D_{\max }$, and against increasing values of such parameter as the size of the eruption increases. Magmawater interaction at very shallow waters has also the potential to increase the efficiency of explosion and the production of very fine ash and ash aggregates (e.g. Sheridan and Wohletz, 1983); however, here we neglect these effects in order to keep our empirical model simple and computationally cheap. This assumption is justified by the fact that the input values used to feed computational models for tephra fallout hazard assessment at many partially submerged volcanoes are commonly obtained from field data that typically account for these effects.

In order to evaluate such sensitivity, in practice we apply the proposed models to $\mathrm{CFc}$, a caldera system which is approximately half-submerged, being formed by two nested calderas originated by two major collapses, the first related to the Campanian Ignimbrite eruption, which occurred about $39 \mathrm{ka}$ ago (e.g. Costa et al., 2012), and the Neapolitan Yellow Tuff eruption, which occurred about $15 \mathrm{ka}$ ago (e.g. Orsi et al., 1992). In the last $15 \mathrm{ka}, \mathrm{CFc}$ volcanic activity has been very intense producing about 50 eruptions (Smith et al., 2011), the last (forming Monte Nuovo tuff-cone) occurring in AD 1538 (Guidoboni and Ciuccarelli, 2011). Recently, the centre of $\mathrm{CFc}$ has been affected by a few major bradyseismic events, the latter two respectively in the early 1970s and 1980s, which generated almost $2 \mathrm{~m}$ of maximum ground deformation each (Orsi et al., 1999). Recent compositional anomalies of fumaroles together with major and minor bradyseismic events might suggest a new volcanic unrest at CFc (Chiodini et al., 2012).

Our PVHAs are based on the Bayesian Event Tree for Volcanic Hazard (BET_VH, see Marzocchi et al., 2010). Like in Selva et al. (2010), we use a finite number of eruptive scenarios to represent the full variability of the next possible eruption, by defining the possible vent locations (seven hundreds, Selva et al., 2012a) and a range of expected eruptive styles/sizes (dome-forming effusive, small, medium and large explosive eruptions) for $\mathrm{CFc}$ (Orsi et al., 2009; Costa et al., 2009). By means of BET_VH, we properly weight each eruptive scenario with its own probability of occurrence. As in Selva et al. (2010), tephra dispersal for each eruptive scenario is described using the simulation results Costa et al. (2009) obtained by applying the analytical tephra deposition model HAZMAP (Macedonio et al., 2005), for all the potential vent locations and explosive eruptive styles/sizes, and considering a statistically significant set of wind profiles. Compared to Selva et al. (2010), here we also consider the probability of eruption occurrence at $\mathrm{CFc}$ in 50 years as inferred in Selva et al. (2012a), obtaining the unconditioned PVHA for tephra fallout.

As we mentioned above, for the sake of simplicity, here we neglect the possible enhancement in explosivity due to
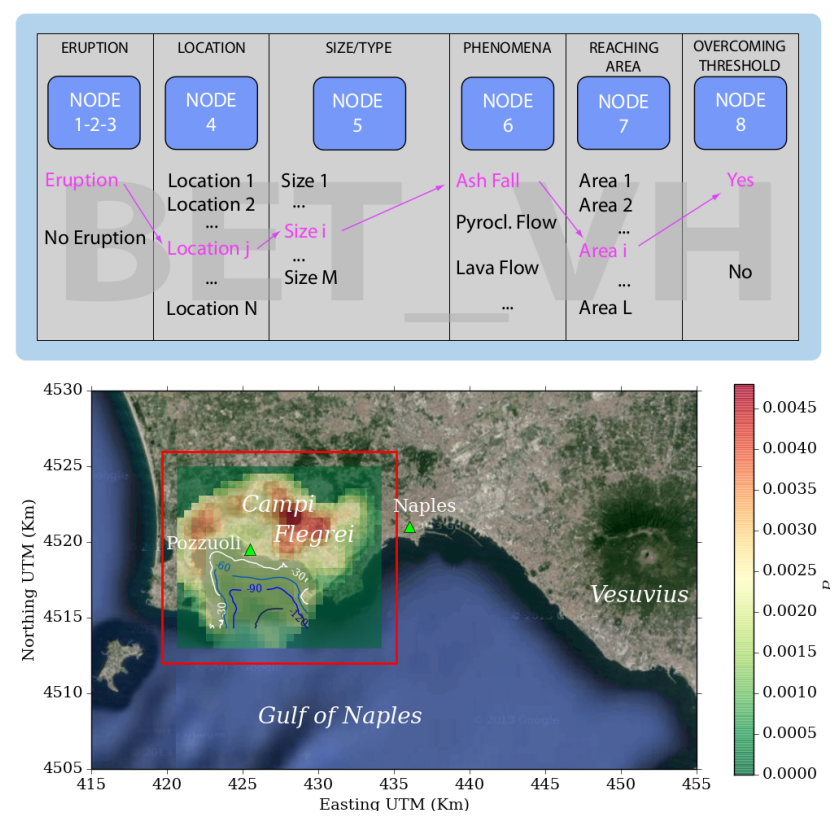

Figure 1. General event tree scheme for BET_VH after Marzocchi et al. (2010) (upper panel). Campi Flegrei caldera (red rectangle) and vent opening probability map of the 700 vents after Selva et al. (2012b) (bottom panel). Isobaths at 30,60, 90 and $120 \mathrm{~m}$ depth in the Gulf of Pozzuoli are shown (contour lines from white to dark blue).

magma-water interaction (e.g. Sheridan and Wohletz, 1983). However, we remark that the large proportion of fine tephra observed in $\mathrm{CFc}$ eruptive products (due to magma-water interaction) is, in principle, considered in the empirical total grain size distribution used as input for the HAZMAP model (Costa et al., 2009).

The final results of each PVHA are presented as Bayesian probability maps, showing the probability of exceeding a threshold of $3 \mathrm{kPa}$ of tephra load in the target domain and within a time window of 50 years. We then check the sensitivity of the effect of water in the case of $\mathrm{CFc}$ by comparing the PVHA resulting from the presented model with the reference PVHAs and with their statistical mixing.

\section{Water depth and subaerial tephra production: modelling approaches}

In this section we describe how the effect of the sea has been quantitatively taken into account. In order to distinguish a possible different behaviour between inland and submarine eruptions, we introduce a variability of the probability in subaerial tephra production as a function of the vent position. In other words, the probability of tephra production at node 6 (see Fig. 1, upper panel) of BET_VH (Marzocchi et al., 2010) depends on the water depth above the submerged vent. In particular, we define four different hypotheses (namely H1, H2, $\mathrm{H} 3$ and $\mathrm{H} 4)$ : the first two ( $\mathrm{H} 1$ and $\mathrm{H} 2)$ represent the end- 
member models, $\mathrm{H} 3$ is the statistical mixing of $\mathrm{H} 1$ and $\mathrm{H} 2$, and $\mathrm{H} 4$ introduces the inhibiting effect of the overlaying water for offshore vents by using some empirical considerations (Mastin and Witter, 2000).

1. In this case we do not take into account the presence of water above the offshore vents; in other words, we rely on the assumption that both inland and offshore vents have the same capability to produce subaerial tephra. In general, this corresponds to set a uniform best guess probability at node $6\left(P_{\mathrm{N} 6}=P_{0}\right)$ for all the vents. This is the same assumption adopted, for example, by Selva et al. (2010) for CFc and is the most common approach applied in tephra fallout hazard assessment up to now.

2. In this case we assume that if waters are deeper than $10 \mathrm{~m}$, the production of subaerial tephra is totally suppressed. The cut-depth of $10 \mathrm{~m}$ is here assumed as a possible order-of-magnitude size of uplift precursor to explosive eruptions (e.g. Guidoboni and Ciuccarelli, 2011), and also a typical size of cones that form in the first phases of eruptions. In other words, if the vent is at such depth or shallower, in a short time before (in case of precursor uplift) or after (due to cone formation) the eruption onset, the activity will turn into subaerial, and the overall effect of water on subaerial tephra production will be negligible (neglecting the effects of an increase in explosivity due to magma-water interaction discussed above). Following this assumption, this hypothesis considers two typologies of eruptive vents only:

a. inland or in shallow water (i.e. water shallower than $10 \mathrm{~m}$ ) having a maximum capability of producing subaerial tephra $\left(P_{\mathrm{N} 6}=P_{0}\right)$;

b. offshore deep water (i.e. water deeper than $10 \mathrm{~m}$ ) having a totally null capability of producing subaerial tephra $\left(P_{\mathrm{N} 6}=0\right)$.

3. This hypothesis consists in assuming that the hazard can be modelled by a statistical mixing of the two opposite end-members described in $\mathrm{H} 1$ and $\mathrm{H} 2$ hypotheses. In this view, the results obtained from $\mathrm{H} 1$ and $\mathrm{H} 2$ are statistically combined into $\mathrm{H} 3$ by representing the latter with a sample composed by the union of two randomly sampled subsets of values (one subset from $\mathrm{H} 1$ and one from $\mathrm{H} 2$ ). The relative numerosity of the two subsets is a proxy of the relative weight assigned to $\mathrm{H} 1$ and $\mathrm{H} 2$, and might be assigned according to the credibility of the two hypotheses for the considered volcano: for example, depending on the knowledge of the local bathymetry, if the sea is very shallow throughout the submerged part, one might want to assign a higher weight to $\mathrm{H} 1$, and vice versa.

4. This empirical hypothesis is based on the set of observations on subaqueous eruptions described by Mastin and
Witter (2000), who reported very few cases of subaqueous eruptions from depths greater than $100 \mathrm{~m}$ that have breached the water surface, and none for water depth over $400 \mathrm{~m}$. To account for this empirical observations we simply assume that, for submarine vents, $P_{\text {N6 }}$ linearly decreases with the water depth $D$, from a minimum depth $D_{\min }$ up to a maximum depth $D_{\max }$, at which the water column completely suppresses the production of subaerial tephra. This empirical relationship can be expressed as

$P_{\mathrm{N} 6}= \begin{cases}P_{0} & D<D_{\min } \\ P_{0}\left(1-\frac{D-D_{\min }}{D_{\max }-D_{\min }}\right) & D_{\min } \leq D \leq D_{\max } \\ 0 & D>D_{\max } .\end{cases}$

Here we set $D_{\min }=10 \mathrm{~m}$, for the same reason explained in $\mathrm{H} 2$, and $D_{\max }=300 \mathrm{~m}$, after a sensitivity analysis performed at CFc and described in Sect. 4. It is important to remark that, even though we use Eq. (1) in the BET_VH model, nevertheless the formula is general and can be used in other probabilistic frameworks to compute the probability of tephra production given an explosive eruption in submerged environments.

\section{Application to CFc case study: PVHA input}

As mentioned above, for our PVHAs at CFc we rely on the model BET_VH (Marzocchi et al., 2010), which is based on the event tree described in Fig. 1 (upper panel). Our target domain is a $70 \mathrm{~km} \times 70 \mathrm{~km}$ area including $\mathrm{CFc}$ and the whole area in front of the Gulf of Naples (Fig. 1, bottom panel) where a few millions of people live. In the following we summarize the definitions of the various nodes of BET_VH and describe how we take into account the effect of the sea with respect to the tephra production at node 6 :

- Nodes 1-3 represent the probability of experiencing an eruption in the time window $\Delta t$, that here we set to 50 years as typical for long-term hazard. As regards the probability density function (pdf) for nodes $1-3$, we assume a Poissonian process with annual rate 12 times the monthly probability of eruption computed by Selva et al. (2012b), obtaining a best guess probability for an eruption at $\mathrm{CFc}$ in 50 years of about $40 \%$.

- Nodes 4 and 5 represent the conditional probability to experience a specific eruptive scenario - that is, an eruption from a given vent position (Node 4) and of a given size (Node 5). For the spatial probability distribution (Node 4) of vent opening we rely on results by Selva et al. (2012a) and shown in Fig. 1 (bottom panel). For the probability of eruptive sizes (Node 5), as in Orsi et al. (2009) we consider four different size classes based on the geological history of CFc (Costa et al., 2009; Orsi et al., 2009): (i) a lava dome eruption 


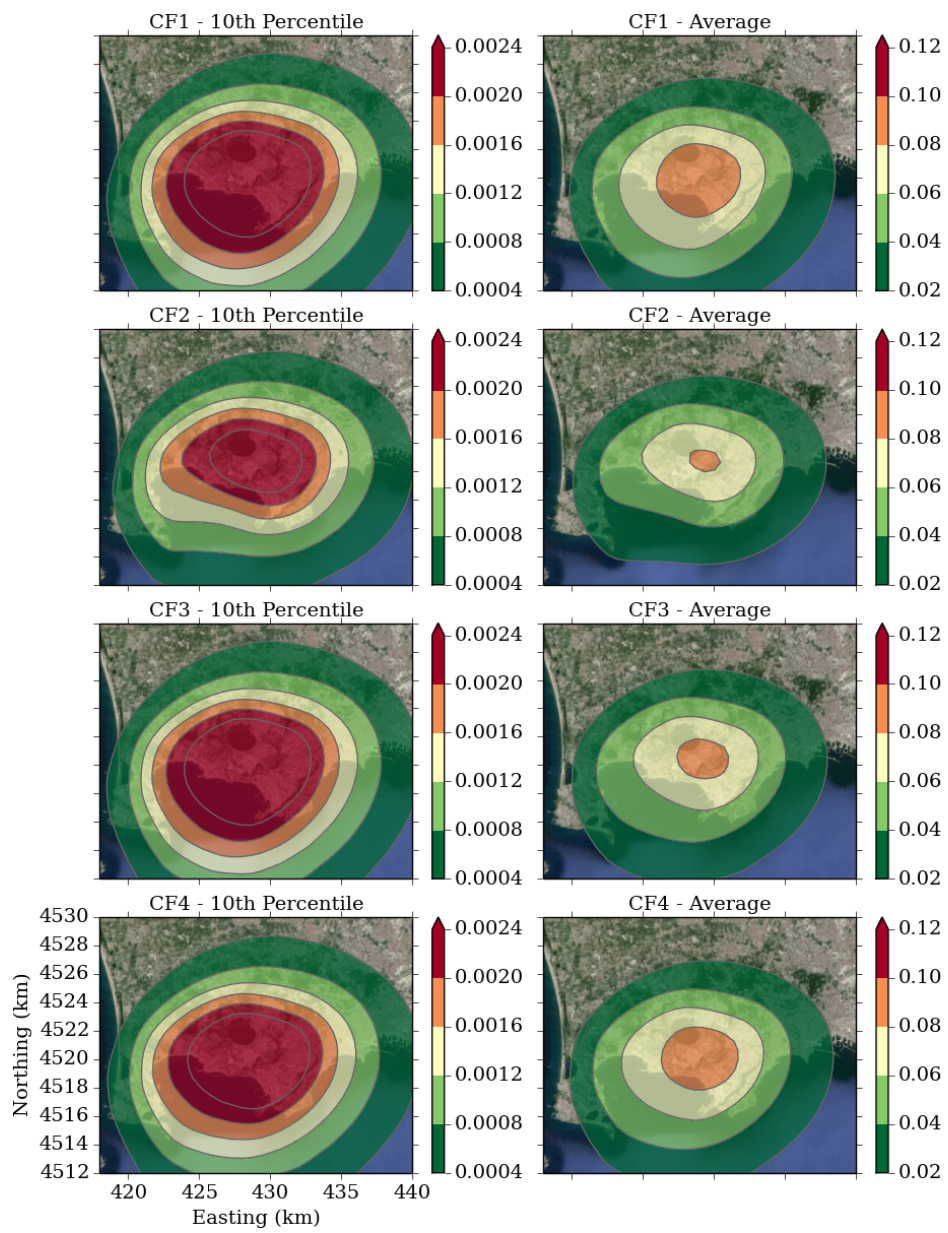

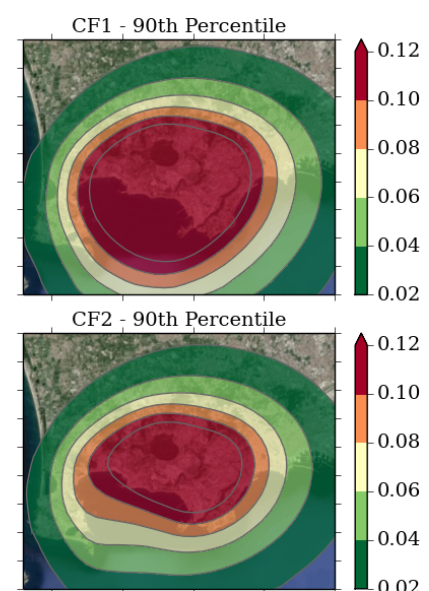

CF3 - 90th Percentile

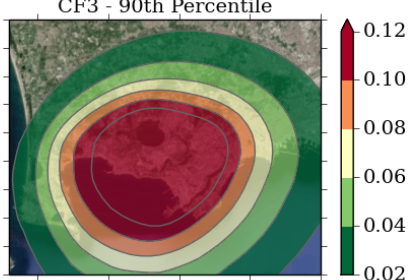

CF4 - 90th Percentile

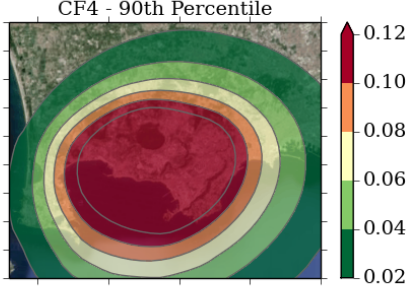

Figure 2. PVHA based on $\mathrm{H} 1, \mathrm{H} 2, \mathrm{H} 3$ and $\mathrm{H} 4$ hypotheses at $\mathrm{CFc}$ are shown from top to bottom respectively (CF1, CF2, CF3 and CF4). The middle column panels show the best guess (average) value for the probability of observing a tephra load larger than $3 \mathrm{kPa}$ in 50 years due to $\mathrm{CFc}$ magmatic eruptions, according to the PVHA model adopted. Left and right column panels show respectively the corresponding 10 th and 90 th percentiles.

(not producing tephra fallout), (ii) a small explosive size similar to Averno 2 eruption, (iii) a medium explosive size similar to Astroni 6 eruption, and (iv) a large explosive size similar to Agnano-Monte Spina eruption (Costa et al., 2009).

- Nodes 6-8 represent the impact due to a specific eruptive scenario. At Node 6 we assess the probability of tephra production given an eruption of a given size from a given vent. Such probability is parameterized according to different possible hypotheses, as explained in Sect. 2. In particular, we assume $P_{0}=1$ for all the explosive sizes and $P_{0}=0$ for the lava dome eruptions. Nodes 7 and 8 represent the conditional probability (given a specific eruptive scenario) that tephra covers different points (Node 7) in the target domain and overcomes a given intensity of tephra load (Node 8), here set at $3 \mathrm{kPa}$ as a representative threshold for potential roof damage (e.g. Macedonio et al., 2005). For each explosive size, such conditional probabilities are estimated as in Selva et al. (2010), using 1000 HAZMAP simulations of tephra deposits randomly sampled from the 13149 ones performed by Costa et al. (2009). The HAZMAP input parameters of the three reference explosive eruptive sizes are the same as listed in Table 3 in Selva et al. (2010).

\section{Results and discussion}

By modelling with BET_VH the water effect at CFc under the four different hypotheses H1, H2, H3 and H4, we obtain four different PVHAs for the target region, respectively labelled in the following as $\mathrm{CF} 1, \mathrm{CF} 2, \mathrm{CF} 3$ and $\mathrm{CF} 4 . \mathrm{CF} 3$ is the statistical mixing of $\mathrm{CF} 1$ and $\mathrm{CF} 2$, giving equal weight to the two, as we have no evidence that one of the two hypotheses $\mathrm{H} 1$ and $\mathrm{H} 2$ could be more reliable than the other. In Fig. 2 we report the results for the four PVHAs, displayed as maps 

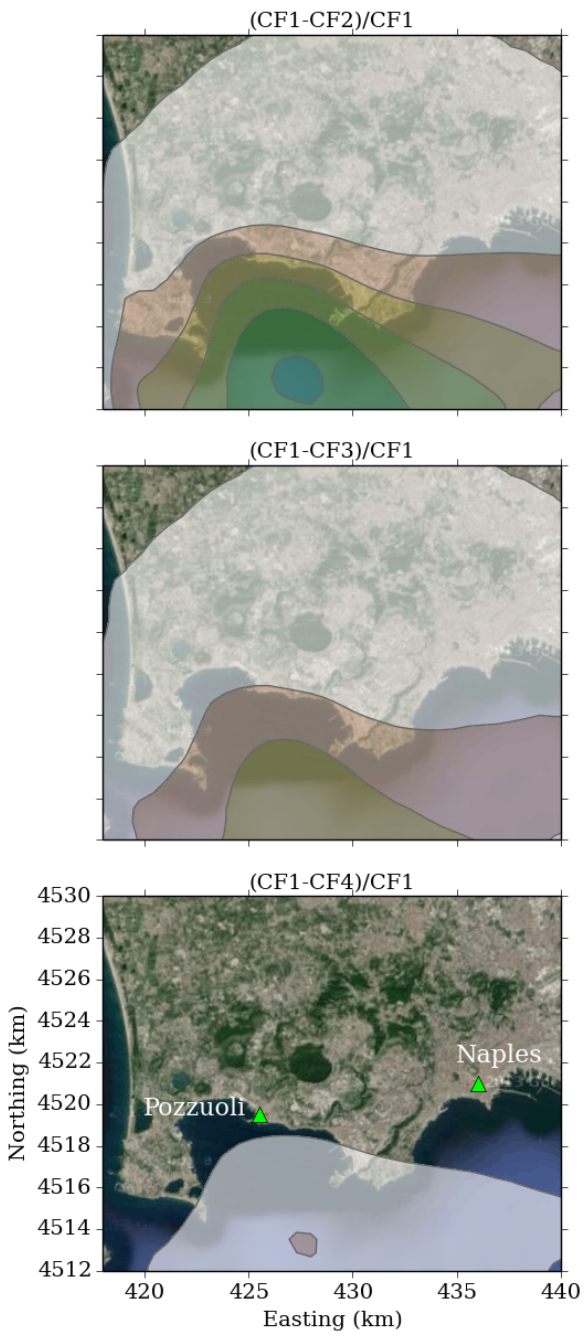
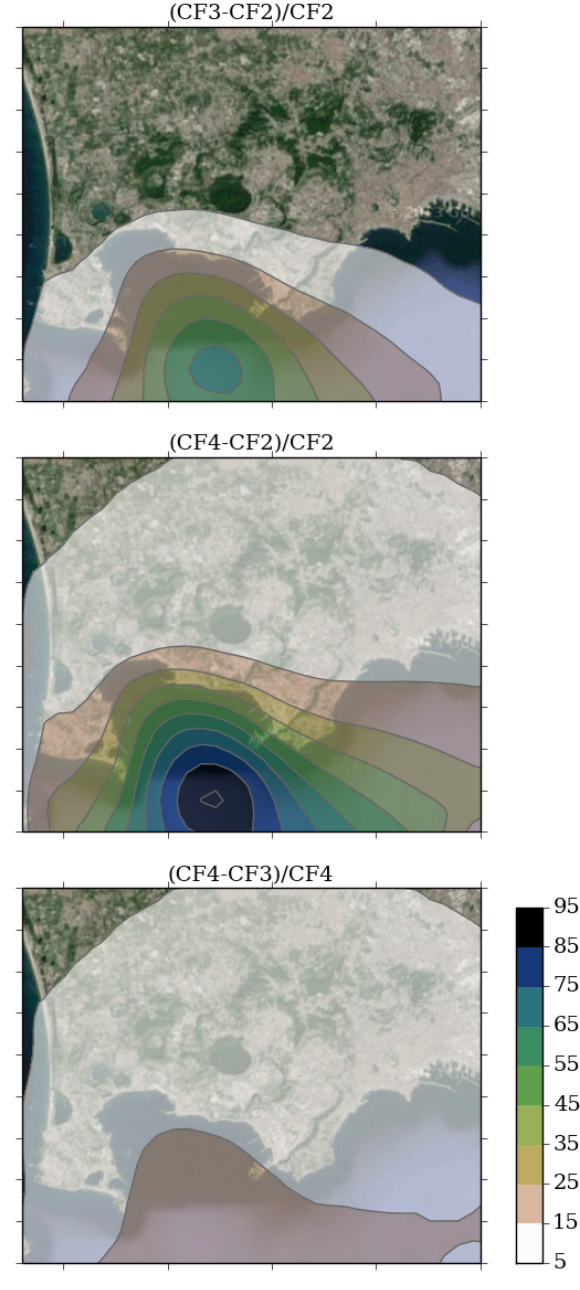

Figure 3. Percent variation (\%) between $\mathrm{CF} 1$ and $\mathrm{CF} 2$ (top left panel), between CF1 and CF3 (middle left panel) and between CF1 and CF4 (bottom left panel) relative to $\mathrm{CF} 1$ (in terms of average probability to overcome a threshold equal to $3 \mathrm{KPa}$ in a time window of 50 years). Similarly, percent variations between $\mathrm{CF} 3$ and $\mathrm{CF} 2$, and $\mathrm{CF} 4$ and $\mathrm{CF} 2$ relative to $\mathrm{CF} 2$ are given in top and middle right panels, respectively. Bottom right panel shows the percent variation between $\mathrm{CF} 4$ and $\mathrm{CF} 3$ relative to $\mathrm{CF} 4$.

showing the best guess (mean) probability of experiencing a tephra load larger than $3 \mathrm{kPa}$ in 50 years. We also report, for each of these maps, the 10th and 90th percentile maps, in order to provide an idea of the epistemic uncertainty associated with the best guess maps.

As mentioned above, for CF4 we set $D_{\max }=300 \mathrm{~m}$. However, in order to check the effect of this assumption we used different values for $D_{\max }$ (from 200 to $400 \mathrm{~m}$ ). Results using such different values show no significant changes in CF4 results; the same applies if we consider increasing values of $D_{\text {max }}$ as the size increases $(200,300$ and $400 \mathrm{~m}$ for respectively small, medium and large explosive eruptions). However this insensitivity to $D_{\max }$ might be due to the shallow bathymetry in the Gulf of Pozzuoli, where maximum water depth is about $150 \mathrm{~m}$, and may not be generalizable to volcanic areas characterized by deeper bathymetry.
The overall feature resulting from a comparison of the four PVHAs is that the maximum of difference is to the southeast of the submerged part of the caldera. This is due to a combination of factors very peculiar to CFc: the submerged part of the caldera has a much lower probability of vent opening (Selva et al., 2010), compared to the subaerial part (see Fig. 1, bottom panel), and the prevalent wind direction is towards the SE (Costa et al., 2009), away from the coastline. This implies that the influence of the sea on the tephra fallout hazard posed by $\mathrm{CFc}$ eruptions is mostly relevant offshore, while on land it may be relevant only within the caldera and in the western part of the municipality of Naples. This can be better visualized in Fig. 3, where, in the left column, the relative differences in terms of PVHA are highlighted by showing residual probability between $\mathrm{CF} 1$ and $\mathrm{CF} 2, \mathrm{CF} 1$ and $\mathrm{CF} 3$, and $\mathrm{CF} 1$ and $\mathrm{CF} 4$ respectively, all divided by $\mathrm{CF} 1$ (which is 
by definition the model implying the largest hazard). More specifically, the maximum relative differences are offshore, and respectively around 50,30 and $15 \%$, while inland they are about 30, 20 and $10 \%$. Such differences are all well captured by our estimate of the epistemic uncertainty in the most commonly used reference model CF1. However, this may be different at other (partially or totally) submerged volcanic systems (Bebbington and Cronin, 2010; Sandri et al., 2012). Similarly, we show the residual probability between $\mathrm{CF} 3$ and $\mathrm{CF} 2$, and $\mathrm{CF} 4$ and $\mathrm{CF} 2$ respectively, all divided by $\mathrm{CF} 2$ (see top and middle panels in the right column of Fig. 3). With $\mathrm{CF} 4$, we try to capture the main feature contained in the data by Mastin and Witter (2000), i.e. a decrease in explosivity as vent depth increases. In this view, the latter results emphasize the evident underestimation of model CF2 offshore and in the coastal areas of Pozzuoli and Posillipo. Moreover, we calculate the relative variation between $\mathrm{CF} 4$ and $\mathrm{CF} 3$, which shows similar results between the two, with a general underestimation of $\mathrm{CF} 3$ respect with $\mathrm{CF} 4$ (Fig. 3, bottom right panel). The maximum variation on land, although within the uncertainty estimated in each model, is below $15 \%$ and never exceeds $25 \%$ offshore. As a consequence of this similarity, we can argue that both $\mathrm{CF} 3$ and $\mathrm{CF} 4$ can be used to estimate the effect of the sea on the final PVHA applied to CFc.

As we have stressed above, the variations found in the hazard assessment computed in this study making different hypotheses is due to the features of $\mathrm{CFc}$ that are not general for other volcanoes, as for example in the case of the Auckland Volcanic Field (Bebbington and Cronin, 2010; Sandri et al., 2012). In such cases, the sensitivity of PVHA to the effect of the sea might be important also at inland locations. Furthermore, the value of the differences in PVHA obtained here for $\mathrm{CFc}$ might not be negligible when using the hazard assessment to take rational decisions for risk mitigation based for example on cost/benefit analysis (e.g. Marzocchi and Woo, 2009), as in general they might change significantly the areas where an action should or should not be taken.

\section{Conclusions}

We have explored the effect of potentially offshore eruptions on the PVHA for tephra fallout, by comparing four different hypotheses for tephra production from submerged vents. The proposed models $\mathrm{H} 3$ and $\mathrm{H} 4$ seem to be a reasonable way to account for submerged vent locations, at least in our application at CFc. In such application, the differences among the four proposed PVHAs are within the epistemic uncertainty attached to the most commonly used H1 model, and are mostly confined to offshore areas. However, this might be a consequence of two peculiarities of CFc (i.e. the low probability of offshore vent opening and the SE direction of prevalent winds). In addition, such differences might not be negligible in terms of risk mitigation strategies and the effects could be completely different for other volcanoes worldwide. Both H3 and H4 models can, in principle, be applied to any other (partially or totally) submerged volcanic system. However, while for $\mathrm{CFc}$ they provide similar results, this might not be generalized to other volcanoes, since their results depend on local features of the considered volcano (i.e. bathymetry, spatial probability of vent opening, prevailing wind field compared to coastline direction, etc). In conclusion, we argue that a comparison with PVHAs based on $\mathrm{H} 3$ and $\mathrm{H} 4$ assumption might be a simple and computationally cheap strategy to quantify the effect of submerged vents on subaerial tephra production and related hazard.

The proposed contribution neglects possible efficient magma-water interaction at very shallow waters, that should be considered in future works on more comprehensive PVHA for tephra fallout and other phenomena, to further explore the sensitivity of hazards to such effect.

Acknowledgements. The work has been developed in the framework of "ByMuR" (http://bymur.bo.ingv.it), a project funded by the Italian Ministry of Education, Universities and Research, "V1: Probabilistic Volcanic Hazard Assessments", a project funded by the Italian Civil Protection Department, and "MEDSUV: MEDiterranean SUpersite Volcanoes", a project funded by EU (FP7). A. Costa acknowledges also the EU Research Project (FP7) "VERTIGO".

Edited by: G. Macedonio

Reviewed by: A. Felpeto and one anonymous referee

\section{References}

Bebbington, M. S. and Cronin, S. J.: Spatio-temporal hazard estimation in the Auckland Volcanic Field, New Zealand, with a new event-order model, B. Volcanol., 73, 55-72, 2010.

Chiodini, G., Caliro, S., De Martino, P., Avino, R., and Gherardi, F.: Early signals of new vol- canic unrest at Campi Flegrei caldera? Insights from geochemical data and physical simulations, Geology, 40, 943-946, 2012.

Costa, A., Dell'Erba, F., Di Vito, M. A., Isaia, R., Macedonio, G., Orsi, G., and Pfeiffer, T.: Tephra fallout hazard assessment at the Campi Flegrei caldera (Italy), B. Volcanol., 71, 259-273, 2009.

Costa, A., Folch, A., Macedonio, G., Giaccio, B., Isaia, R., and Smith, V. C.: Quantifying volcanic ash dispersal and impact from Campanian Ignimbrite super-eruption, Geophys. Res. Lett., 39, L10310, doi:10.1029/2012GL051605, 2012.

Guidoboni, E. and Ciuccarelli, C.: The Campi Flegrei caldera: historical revision and new data on seismic crises, bradyseisms, the Monte Nuovo eruption and ensuing earthquakes (twelfth century 1582 AD), B. Volcanol., 73, 655-677, 2011.

Macedonio, G., Costa, A., and Longo, A.: A computer model for volcanic ash fallout and assessment of subsequent hazard, Comput. Geosci., 31, 837-845, 2005.

Marzocchi, W. and Woo, G.: Principles of volcanic risk metrics: theory and the case study of Mount Vesuvius and Campi Flegrei, Italy, J. Geophys. Res., 114, B03213, doi:10.1029/2008JB005908, 2009. 
Marzocchi, W., Sandri, L., and Selva, J.: BETVH: a probabilistic tool for long-term volcanic hazard assessment, B. Volcanol., 72, 705-716, 2010.

Mastin, L. G. and Witter, J. B.: The hazards of eruptions through lakes and seawater, J. Volcanol. Geoth. Res., 97, 195-214, 2000.

Orsi, G., D'Antonio, M., de Vita, S., and Gallo, G.: The Neapolitan Yellow Tuff, a large-magnitude trachytic phreatoplinian eruption: eruptive dynamics, magma withdrawal and caldera collapse, J. Volcanol. Geoth. Res., 53, 275-287, 1992.

Orsi, G., Civetta, L., Del Gaudio, C., de Vita, S., Di Vito, M. A., Isaia, R., Petrazzuoli, S. M., Ricciardi, G. P., and Ricco, C.: Short-term ground deformations and seismicity in the resurgent Campi Flegrei caldera, Italy: an example of active blockresurgence in a densely populated area, J. Volcanol. Geoth. Res., 91, 415-451, 1999.

Orsi, G., Di Vito, M. A., and Isaia, R.: Volcanic hazard assessment at the restless Campi Flegrei caldera, B. Volcanol., 66, 514-530, 2004.

Orsi, G., di Vito, M. A., Selva, J., and Marzocchi, W.: Long-term forecast of eruption style and size at Campi Flegrei caldera (Italy), Earth Planet. Sc. Lett., 287, 265-276, 2009.

Sandri, L., Jolly, G., Lindsay, J., Howe, T., and Marzocchi, W.: Combining long- and short-term probabilistic volcanic hazard assessment with cost-benefit analysis to support decision making in a volcanic crisis from the Auckland Volcanic Field, New Zealand, B. Volcanol., 74, 705-723, 2012.
Selva, J., Costa, A., Marzocchi, W., and Sandri, L.: BETVH: exploring the influence of natural uncertainties on long-term hazard from tephra fallout at Campi Flegrei (Italy), B. Volcanol., 72, 717-733, 2010.

Selva, J., Marzocchi, W., Papale, P., and Sandri, L.: Operational eruption forecasting at high-risk volcanoes: the case of Campi Flegrei, Naples, J. Appl. Volcanol., 1, 1-14, 2012a.

Selva, J., Orsi, G., Di Vito, M. A., Marzocchi, W., and Sandri, L., Probability hazard map for future vent opening at Campi Flegrei caldera, Italy, B. Volcanol., 74, 497-510, 2012b.

Selva, J., Costa, A., Sandri, L., Macedonio, G., and Marzocchi, W.: Probabilistic short-term volcanic hazard in phases of unrest: a case study for tephra fallout, J. Geophys. Res., 119, 8805-8826, 2014.

Sheridan, M. F. and Wohletz, K. H.: Hydrovolcanism: basic considerations and review, J. Volcanol. Geoth. Res., 17, 1-29, 1983.

Smith, V. C., Isaia, R., and Pearce, N. J. G.: Tephrostratigraphy and glass compositions of post-15 kyr Campi Flegrei eruptions: implications for eruption history and chronostratigraphic markers, Quaternary Sci. Rev., 30, 3638-3660, 2011. 